\title{
Treinamento COGNitivo DA MEMÓRIA DE TRABALHO EM ADULTOS IDOSOS
}

Tania Maria Netto

A presente tese de doutorado aborda a temática treinamento da memória de trabalho em adultos idosos na interface da psicologia clínica e neurociência. Foi composta por dois estudos: um teórico e outro empírico. O estudo teórico teve como objetivo revisar a literatura dos últimos dez anos em busca de um panorama sobre estudos de intervençôes neuropsicológicas da memória de trabalho em amostras com adultos. O estudo empírico visou a verificar se houve diferenças de desempenho em testes neuropsicológicos aplicados pré- e pós-intervenção entre um grupo de adultos saudáveis que participaram de um treinamento de memória da trabalho e um grupo de controles saudáveis que participaram de encontros de socializações.

\section{BANCA:}

Jesus Landeira Fernandez (Orientador)

Rochele Paz Fonseca (Coorientador)

Ana Paula Almeida de Pereira

Elie Cheniaux Junior

Flavia Sollero de Campos

Paula Rui Ventura

Data da defesa: 9/04/2010 